\title{
Influence of tides, bathymetry, lithology and regional flows on the salinization process in nature area the Rammegors
}

\author{
Ilja America ${ }^{1}$, Perry de Louw ${ }^{2}$, George Bier ${ }^{1}$, Sjoerd van der Zee ${ }^{1}$ \\ 1 Environmental Sciences, Wageningen University, Wageningen, Netherlands \\ 2 Deltares
}

\begin{abstract}
Nature area Rammegors, which has recently been transformed from a fresh inner-dyke nature area to a salt tidal area. Due to this transformation, salt water is infiltrating in a fresh waterlens. This salinisation process is investigated in more detail by two- and three dimensional models together with mearsurements in the area. Zeeland project FRESHEM has provided detailed isohaline maps of the area and Deltares is making transient isohaline maps based on measurements made by an ERT-cable which is situated in Rammegors. These data has been and will be used to investigate which factors; bathymetry, lithology, tides or regional groundwater flow, will have the largest impact on the salinization process in Rammegors. This investigation shows that discretization size has an influence on the speed and spatial distribution of salt plumes. Lithology has the largest influence on the salinization process, followed by bathymetry. Spring and neap tides do differ from the normal tides situation only when bathymetry is not taken into account.
\end{abstract}

\section{INTRODUCTION}

Rammegors (figure 1) was still an inner-dike nature reserve near the island of Tholen, wedged by the Scheldt-Rhine channel on the one hand and the Easternscheldt on the other, 40 years ago. It took part of a dynamic tidal system consisting of deep channels, tidal flats and salt marshes (De Louw et al., 2016). This changed with the construction of the ScheldtRhine canal, 40 years ago. Rammegors was isolated for that part of the Easternscheldt and changed from an open tidal area to a fresh inner-dike nature area. Typical salty tidal nature that is unique in Europe, was lost by the creation of Rammegors. This unique salty tidal nature is still present in the Easternscheldt. However, since the construction of the storm surge barrier in 1986, less water has been flowing into and out of the Easternscheldt which result in a decrease in tidal amplitudes, volumes and velocities of the water but most of all, a decrease in sediment exchange. A situation is created where erosion and sedimentation are not in equilibrium with each other. This is called the sand deficit problem or either 'sand hunger'. The ecological value of the area decreases because the surface of intertidal areas is reducing 50 ha per year, on average (De Louw et al., 2016). In order to give this valuable nature more space, the connection between Rammegors and Easternscheldt is restored. This creates a salt tidal area, where salt marshes can thrive again and birds can find food on the mud flats. The Rammegors is therefore completely given back to the Easternscheldt. The recovery of the original Zeeland landscape, but now controlled behind a safe dike. This MSc-study focuses on nature area Rammegors which experiences an unstable density stratification, as heavier seawater lies on top of lighter freshwater, since the connection with the Eastern Scheldt in December 2016. This freshwater forms a lens which was created by precipitation-excess when the Rammegors was embanked by dikes (Pauw, 2015). The unstable density stratification can give rise to free convection (fingering) were salinization occurs much more rapid because advective flow is driven by density differences (Post and Kooi, 2003). 


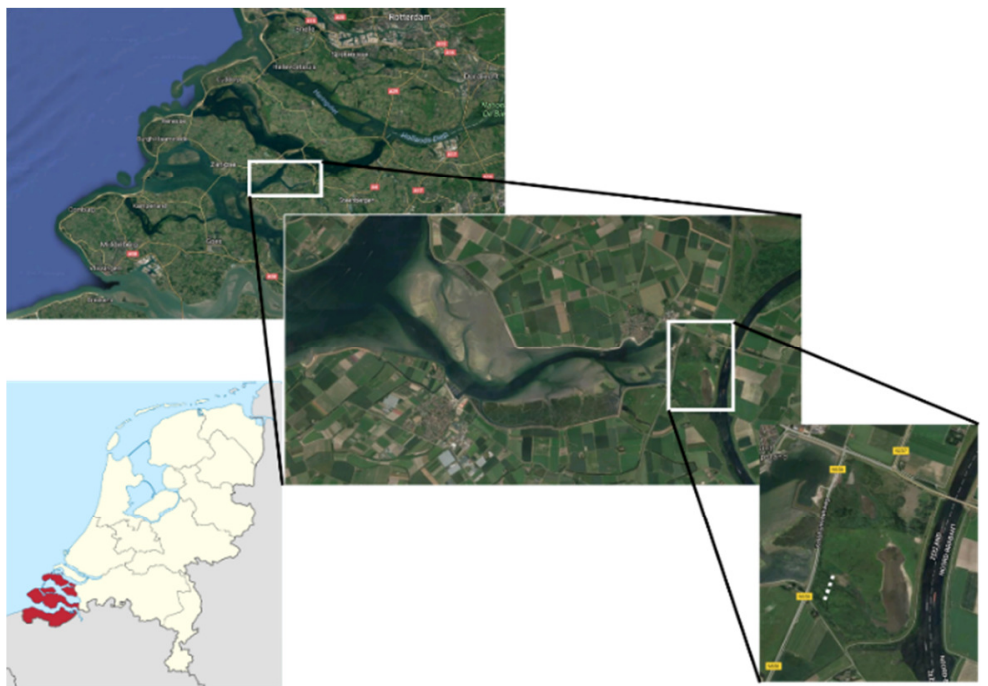

Figure 1. Study area: nature area Rammegors, the Netherlands (Google Maps). Dotted white line is transect where 2 dimensional model will be based upon.

The general scarcity of high-resolution field data is the main cause that the role of density driven fingering triggered by seawater inundation, has not yet fully assessed under field conditions. Many studies have investigated the process of free convection in unstable conditions in the past (Wooding et al. 1997a,b; Simmons et al., 1999; Kinzelbach, 2000; Post et al., 2004). Most of them have focused on small-scale problems and almost no aquifer scale investigations have been done, due to the strict discretization requirements (Kooi et al., 2000).

Many areas in the world (will) experience salinization because of sea level rise. This is mainly caused by lateral seawater intrusion or vertical infiltration during ocean surge inundation (Yu et al., 2016). Especially low-lying estuaries will experience higher grades of salinization in the future because those areas will be inundated earlier (FitzGerald et al., 2008; Ketabchi et al., 2016). Unfortunately, these future inundations will not be controlled and could therefore damage large parts of the world. It is therefore of great importance to understand the salinization process in Rammegors, where inundations are controlled, in order to minimalize damage in possible future inundations all over the world.

The previous mentioned studies have provided much understanding in the free convection process on small scale. The scarcity of high-resolution field data and the low computation ability prevented investigation on larger scales, which could be validated with trustworthy data. Nature area Rammegors is currently changing to a controlled dynamic tidal system consisting of tidal flats and salt marshes. It is therefore the perfect situations to investigate how an area transforms from a freshwater nature area to a saltwater nature area. In the period 2014 and 2015, several electromagnetic measurements has been made commissioned by the province of Zeeland, Deltares, BGR and TNO for the Zeeland-project FRESHEM. These electromagnetic measurements gives information about the fresh, brackish and saline groundwater. An ERT-cable has been installed by Deltares to measure the salinization process in more detail during time. These isohaline images are still in development and are hopefully finished in June, so they can be showed during the SWIM.

The main goal of this MSc-studyis to investigate which factors; bathymetry, lithology, tides or regional groundwater flow, will have the largest impact on the salinization process in Rammegors. The influence of discretization size, is also be investigated. 


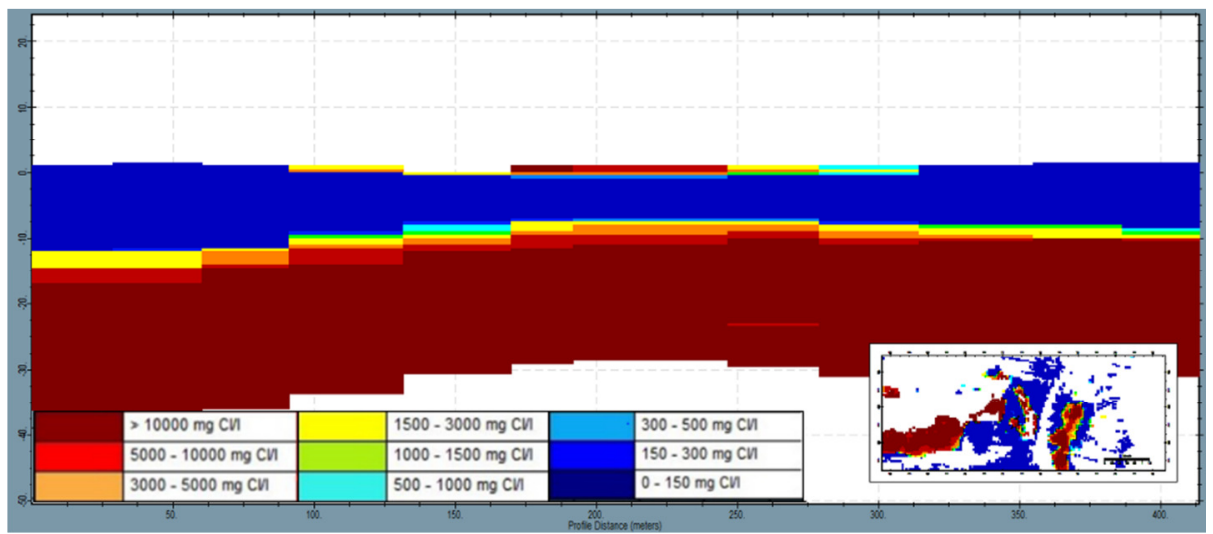

Figure 2. Isohaline FRESHEM map of 2D transect.

\section{METHODS}

In order to investigate how tides, bathymetry, lithology and regional groundwater flow influence free convection and salinization processes in nature area the Rammegors, a 2 dimensional model has been created in a generic MODFLOW/MT3DMS-based computer program, named SEAWAT in a GMS environment. A first impression of the spatial distribution of the chloride concentrations in March 2015 is made with the FRESHEM data of Rammegors. Figure 2 shows the isohaline map of the transect (figure 1) made with the FRESHEM data. The thin salt layer which is located at the top of the salt layer is exactly located in the gully where salt water is flowing. It also shows that the fresh water lens which is created in 40 years is 15 meter thick, on average.

A 2 dimensional model has been made to understand the process of free convection in more detail. First, the influence of discretization size on the spatial and temporal scales on the free convection process are investigated. Six different discretization sizes $(0.5,1,2,5,10$ and 25 meter) has been used. The model is based on a transect in the south-west of Rammegors (figure 1). This transect is situated perpendicular to the hydraulic heads, therefore no sideways fluxes are expected. Some parts of this transect will be inundated always/periodically/never due to its bathymetry and tides. Table 1 shows the implementation of the different factors. The lower elevated areas, which are present due to bathymetry, will always be inundated whereas higher elevated areas will periodically be inundated due to the influence of tides. The discretization size with the most detail and relative lowest computational burden will eventually be used for nine different versions where the impact of regional groundwater flow, tides, bathymetry and lithology on the salinization process will be investigated. In the first version (a) the variable density flow will be switched off and in the second version (b) it will be turned on. This second version will be the reference case to which all other versions are compared to . In the third version (c), a simplified bathymetry transect is implemented. Lithology is implemented in the fourth version (d). In fifth till eighth version (e-h), tides, springtide, tides with bathymetry and springtide with bathymetry are implemented, respectively. In the last version (i), all factors are implemented in a combined version.

In the last stage, a 3 dimensional model will be created where all factors will be implemented. In this model, the future perspective of Rammegors will be created. The 3Dmodel is under construction and therefore not shown here. 
Table 1. Implementation of different factors in 2 dimensional model.

\begin{tabular}{|c|c|}
\hline Factor & Implementation \\
\hline Bathymetry & $\begin{array}{l}5 \text { different levels ranging from }+1.42 \mathrm{~m} \text { NAP (left) to }+0.36 \mathrm{~m} \\
\text { NAP (right). }\end{array}$ \\
\hline Lithology & $\begin{array}{c}7 \text { lithological layers, with poorly permeable layers around }-13 \mathrm{~m} \\
\text { NAP and }-25 \mathrm{~m} \text { NAP. }\end{array}$ \\
\hline Tides & Sinusoidal shape of $0.98+0.4 \sin \left(\frac{2 \pi}{\frac{12.4}{24}} * t\right)$ \\
\hline Spring and neap tides & Sinusoidal shape of $0.98+0.2 \sin \left(\frac{2 \pi}{14.75 * 24} * t\right)+0.4 \sin \left(\frac{2 \pi}{12.4} * t\right)$ \\
\hline
\end{tabular}

\section{RESULTS}

\section{Discretization size}

In figure 3 , the concentration contours after 10 years are shown with different discretization sizes, ranging from 0.5 till 25 meter. A clear distinction in plume shapes between the smaller discretization sizes ( 0.5 till 2 meter) and the larger discretization sizes ( 5 till 25 meter) can be observed, whereby the smaller discretization sizes show more detailed plumes. With increasing discretization size the amount of plumes with concentrations higher than $20 \mathrm{~kg} \mathrm{~m}$ 3 increases within the scales till 1 meter. The free convection plumes which are developed with a discretization size of 2 meter, are more emerged and broader than the plumes that were formed at smaller scales. The areas where fresh water flows in the direction of surface are clearly visible when the discretization size is small. This indicates that the heavier salt water can flow downwards and lighter freshwater will flow upwards. The start locations of the different plumes do differ which indicate that there are no preferential start locations.

The concentration contours of the larger discretization sizes show large salt containing areas, which do not look like plumes. The areas become larger when discretization size increases. The locations where no salt is observed are more or less the same but decreases with increasing discretization size. The influence of the boundaries are clearly visible in the models when smaller discretization sizes have been used. The plumes which have formed in the models with larger discretization sizes migrate faster downwards. The salt mass, which is present in earlier stages, is higher and with that the maximum salt mass is reached earlier.

\section{Factors influencing salinization process}

In figure 4 , the concentrations contours for the different factors after 10 years can be observed. By comparing figures $4 \mathrm{a}$ and $4 \mathrm{~b}$ with each other, the influence of density and thus convection becomes clear. In figure $4 \mathrm{a}$, no plumes are present. The salt infiltrates very gradually downwards. The infiltration is influenced by both boundaries as the infiltration goes faster at the left and right boundaries. When only bathymetry is implemented in the model, the plumes have changed to larger salt containing areas and the shape of the original plumes have diminished completely (figure 4c). The model where only lithology is implemented, shows an increase in salt concentration in the upper most layer which forms a dense salty layer (figure 4d). Figures $4 \mathrm{e}$ till $4 \mathrm{~h}$ show how spring and neap tides differ from a normal tide situation where bathymetry is taken into account and not. In the situations where bathymetry is not implemented the salinization process shows the same pattern as the initial situation. The plumes are only smaller, thinner and less dense. The situation where springtides are implemented (figure 4f) shows more plumes than the situation where normal tides are implemented (figure $4 \mathrm{e}$ ). The positions of these plumes are not the same. The 
plumes in the situations where bathymetry (figures $4 \mathrm{~g}$ and $4 \mathrm{~h}$ ) is implemented have more or less the same location and their shapes are almost the same. In the situation where all factors are combined, the influence of bathymetry is clearly visible by the 4 different section of plumes. The plumes are larger when the surface is covered by water for a longer period which is influenced by tides (most right plume). The most left plume, which has no water levels on the left hand side, is also large. The influence of lithology is clearly visible by an abrupt change in concentration distribution.

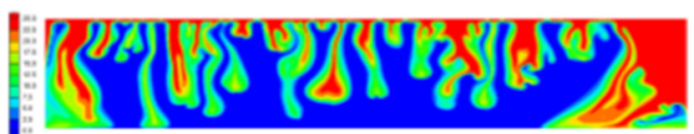

(a) Discitization size of $0.5 \mathrm{~m}$

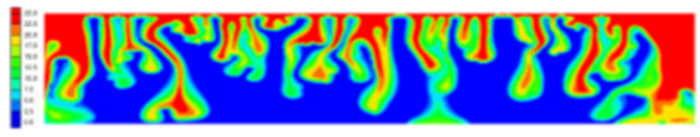

(b) Discitization size of $1 \mathrm{~m}$

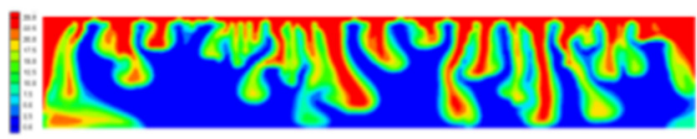

(c) Discitization size of $2 \mathrm{~m}$

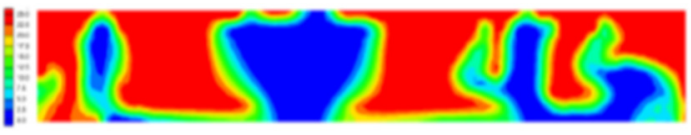

(d) Discitization size of $5 \mathrm{~m}$

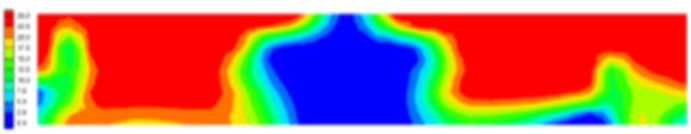

(e) Discitization size of $10 \mathrm{~m}$

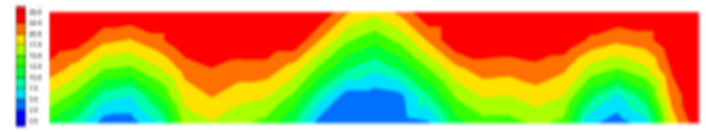

(f) Discitization size of $25 \mathrm{~m}$

Figure 3. Concentration contours after 10 years with different discretization sizes.

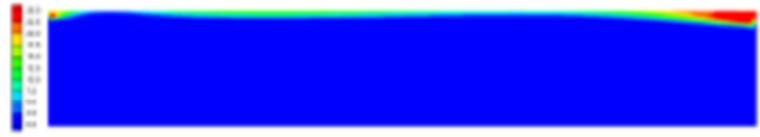

(a) Initial model density excluded

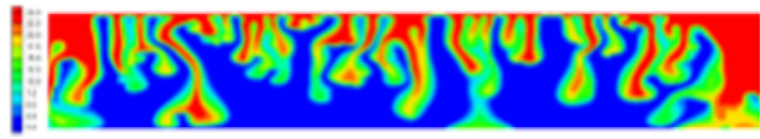

(b) Initial model density included

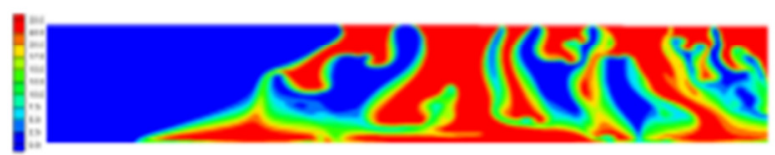

(c) Bathymetry

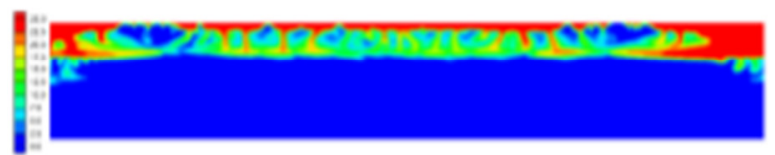

(d) Lithology

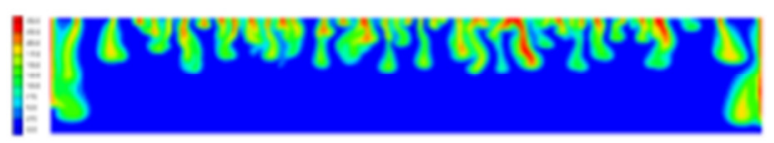

(e) Tides

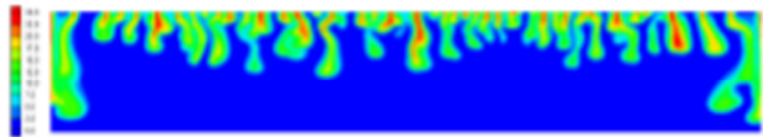

(I) Spring and neap tides

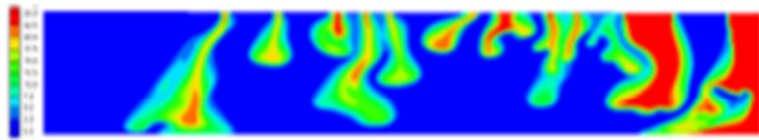

(g) Bathymetry + Tides

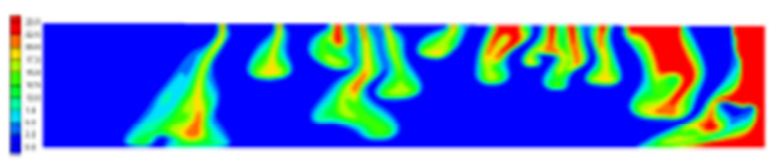

(h) Bathymetry + Spring and neap tides

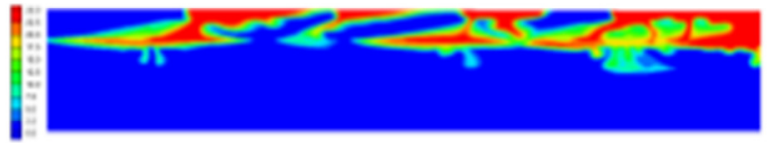

(i) Bathymetry + Lithology + Spring and neap tides

Figure 4. Concentration contour after 10 years for different factors on the salinization process, with a discretization size of 1 meter.

\section{DISCUSSION AND CONCLUSIONS}

In conclusion, discretization size has a major influence if free convection wants to be measured and recorded. There is a large difference between small and large discretization 
sizes, whereas small discretization sizes show free convection plumes and large discretization sizes not. Lithology has the largest influence on the salinization process, followed by bathymetry. The influence of bathymetry is mainly caused by preferential start location, which are located at the transition zones where higher elevated areas begin. Spring and neap tides do differ from the normal tides situation only when bathymetry is not involved.

\section{REFERENCES}

De Louw, P., Ysebaert, T., Bouma, T., B.-M., Van Dalen, J., Van Belzen, J.-S., 2016. Rammegors tidal restoration.

FitzGerald, D. M., Fenster, M. S., Argow, B. A., Buynevich, I. V., 2008. Coastal impacts due to sealevel rise. Annu. Rev. Earth Planet. Sci. 36, 601-647.

Ketavbchi, H., Mahmoodzadeh, D., Ataie-Ashtiani, B., Simmons, C. T., 2016. Sea-level rise impacts on seawater intrusion in coastal aquifers: Review and integration. Journal of Hydrology 535, 235255 .

Kinzelbach, W., 2000. A three-dimensional physical model for verification of variable-density flow codes. In: Calibration and Reliability in Groundwater Modelling: Coping with Uncertainty; Proceedings of the ModelCare'99 Conference Held in Zurich, Switzerland, form 20 to 23 September 1999. No. 265. IAHS, p. 399.

Kooi, H., Groen, J., Leijnse, A., 2000. Modes of seawater intrusion during transgressions. Water resources research 36 (12), 2581-3589.

Pauw, P. S., 2015. Field and model investigations of freshwater lenses in coastal aquifers. Wageningen University.

Post, V. E., Kooi, H., 2003. Rates of salinization by free convection in high-permeability sediments: insights form numerical modelling and application to the dutch coastal area. Hydrogeology Journal $11(5), 549-559$.

Post, V. E. A., et al., 2004. Groundwater salinization processes in the coastal area of the netherlands due to transgressions during the holocene. Ph.D. thesis.

Simmons, C. T., Narayan, K. A., Wooding, R. A., 1999. On a test case for density-dependent groundwater flow and solute transport models: The salt lake problem. Water Resources Research 35 (12), 3607-3620.

Wooding, R., Tyler, S. W., White, I., 1997a. Convection in groundwater below an evaporating salt lake: 1. onset of instability. Water Resources Research 33 (6), 1199-1217.

Wooding, R., Tyler, S. W., White, I., Anderson, P. 1997b. Convection in groundwater below an evaporating salt lake: 2. evolution of fingers or plumes Water Resources Research 33 (6), 1219-1228.

Yu, X., Yang, J., Graf, T., Koneshloo, M., O’Neal, M. A., Michael, H. A., 2016. Impact of topography on groundwater salinization due to ocean surge inundation. Water Resources Research 52 (8), 5794-5812.

Contact Information: Ilja America, Wageningen University, Environmental Sciences Department, Email: ilja.america@wur.nl; 